Ethiopian Journal of Environmental Studies \& Management 9(3): 315 - 325, 2016.

ISSN:1998-0507

doi: http://dx.doi.org/10.4314/ejesm.v9i3.6

Submitted: December 28, 2015

Accepted: May 04, 2016

\title{
INFLUENCE OF KNOWLEDGE MANAGEMENT CRITICAL SUCCESS FACTORS ON ORGANIZATIONAL PERFORMANCE IN NIGERIA CONSTRUCTION INDUSTRY
}

\author{
*IDRIS, K.M. ${ }^{1}$ AND KOLAWOLE, A.R. ${ }^{2}$ \\ ${ }^{1}$ Faculty of Built Environment, Universiti Teknologi Malaysia, Johor, Malaysia \\ ${ }^{2}$ Faculty of Environmental Science, Department of Environmental Planning and \\ Management, Kenyatta University, Nairobi Kenya
}

\begin{abstract}
Knowledge management (KM) is a rising interest in today's business, great number of construction industry turning to knowledge management is gradually increasing because of its definite benefit realize. In project-based industry such as construction, KM is being viewed as a critical success factor in the everyday business of the society. Two hundred and fifteen designated project managers in the Nigerian construction industry were selected using stratified random sampling. A hypothesized model of critical success factors (CSF) of KM, and organizational performance (OP) was tested using structural equation modeling approach (observed variable), and a proposed model was therefore developed. Nine constructs of CSF with their reliability and Cronbach's Alpha coefficient of 0.87, 0.82, $0.74,0.92,0.87,0.82,0.90,0.71$ and 0.70 were tested. All the CSF loadings demonstrated a significant level of 0.94 on the OP. The study serves as a guide to the construction industry on the effect of each CSF outline and deepened reflectiveness of the surpassing role of effective knowledge management in the construction industry.
\end{abstract}

Key Words: Organizational performance, Knowledge management and Critical success factors

\section{Introduction}

Individuals and groups constantly come across and use different insights which they have acquired from small scale, large scale, social and collective business sharing. In other words, knowledge management has existed, in one way or another, for quite some time (Dalkir, 2013). The greatest organizational challenge is how to integrate the incongruent skills, knowhow and knowledge of individual members of the industry into merchandise, development, amenities and finished goods that will benefit the industry as a whole (Choi and Lee, 2002; Cohen and Olsen, 2015).

Most organizations consider knowledge as the most crucial asset to the company which is withheld by the employees and if not carefully managed can vanish along the business line of the construction industry due to various reasons, such as death of staff member, resignation, job mobility or retirement. KM in organizations includes apparatus, schedules and techniques to acquire, create, share and store knowledge among

*Corresponding Author: Idris, K.M.

Email: idriskt@gmail.com 
the employees in the organization (Chen et al., 2009; Donate and de Pablo, 2015). $\mathrm{KM}$ can be viewed as a progression in transmuting individual valuable assets from unstable forms to forms that are preferable for the organizations (Egbu and Robinson, 2005). Some look at KM processes as a scheme, a method and a discipline which deals with manufacture, society, storage, distribution, utilizing and appraising of knowledge to achieve organizational goals (Bosch-Sijtsema and Henriksson, 2014). Ahern et al. (2014) on the other hand, argues that management of knowledge in the construction industry refers to systematic, logical and organizational methods of obtaining or establishing, interactive tacit and explicit knowledge of workers so that other professional workers can make use of it for work efficiency. Thus, Balaid et al. (2014) consider KM as a method of more activity leveraging the ideas and expertise resided in people minds to create respect and values in enhancing effectiveness. Efficient implementation of KM will improve organizations' work quality and reduce cost, time and repetitive mistakes. $\mathrm{KM}$ in construction is crucial and serves as a major driver for innovations, client satisfaction and overall business performance (Chinowsky and Carrillo, 2007).

Jennex et al. (2014) stated that KM is a practice of selectively smearing knowledge from past experience of decision making to current and further decision making in creating values and enhance organizational effectiveness. Jackson et al. (2015) on the other hand, argue that the critical success factors (CSF) of knowledge management is useful as it provides the construction organization with basic requirement for implementing a successful KM initiative and building a successful knowledge management system (KMS). KMS is that system created to enhance the acquisition, creation, capturing, storing and reusing of available knowledge. KMS and KM holistically combine technical and organizational solution to attained the goals of storing knowledge and reuse in ultimately improving organizational performance and individual decision making (Jain et al., 2015). CSF of knowledge management is the activities, technique and processes that should be addressed for successful implementation of $\mathrm{KM}$ in the organization. The techniques and processes need to be encouraged or developed in the organization. Some researcher looked at CSF of KM as an internal issue manageable by an organization (King et al., 2008; Musa et al., 2015). Liebowitz (2006) argues that, for $\mathrm{KM}$ to succeed in any organization; six different elements of CSF must be in order:- namely, knowledge infrastructure and knowledge officers, knowledge ontology, KM strategy and management, incentive for sharing knowledge and organizational culture. The author further suggested that by paving ways for these critical elements, KM would be a key competitive strategy for the organization.

Jennex and Olfman (2006) from their own point of view agree that, KM critical success factors are of decision-making, actions and planning that must be practice if effectiveness and efficiency are to be achieved in the construction organization. CSF of $\mathrm{KM}$ in the organization is grouped of elements that contribute to fruitful project outcomes. CSF of KM can be viewed as satisfactory result areas that will ensure successful competitive performance for the organization. Holsapple and Joshi (2000) 
identified three main classes of critical elements of KM through a descriptive frame work; environmental influence, managerial influence and resource influence. The author further identified factors that conspire to influence each element in the KM. Top management control, coordination and leadership were found crucial in the managerial influence. From other perspective, financial support, identification of knowledge sources, skill level of employees are also very crucial. Environmental factors are said to include technology and culture.

Davenport et al. (1997) on the other hand, suggested eight CSF of KM found to be crucial in construction project. 1) Industry value 2) Organizational infrastructure 3) Standard flexible knowledge structure 4) Culture 5) Motivational practices 6) Different channels for knowledge sharing 7) Support from senor management 8) Clarity of language and purpose. Zhang (2005) and Wang et al. (2014) identified $11 \mathrm{CSF}$ of KM for been crucial for both SEMs and public-private infrastructure development. These factors are; 1) leadership and support 2) IT 3) strategy and planning 4) culture 5) organization infrastructure 6) knowledge management resources 7) conferences, training and education 8) motivational aids 9) processes and activities 10) measurement 11) human resources management.

However, after revising the theories and literatures from different researchers, it becomes very important to identify the key notions and CSF of KM for the construction of a Hypothesized Measurement Model of the CSF for this research and the definition of the hypothesis as shown in Figure 1.

\section{Aims and Objectives of the study}

The aim of the study is to identify how the Knowledge Management process can positively influence Organizational performance. The objectives are:-

1. Identify the critical success factors in the knowledge management process in the Nigerian construction organization.

2. Identify the most prevalent factors that contributed to effective knowledge management process

\section{Hypothesis}

Management of knowledge in the construction organization has been postulated by various researchers, implying that implementation of KM will enhance organizational performance and innovations. Thus, various researchers proposed several key factors in the KM approach; however, few of the key factors were selected for the statistical analysis. On this basis, the main hypothesis was formulated with other sub-hypothesis in order to validate the proposed model in the study.

Based on the review literature presented, the following hypotheses were proposed;

- H1(Main hypothesis): KMP has significant influence on OP

- H1a: Strategy can positively influence KMP

- H1b: Culture can positively influence KMP

- H1c: Leadership can positively influence KMP

- H1d: Organizational infrastructure can positively influence KMP

- H1e: IT can positively influence KMP

- H1f: Knowledge management technical activities can positively influence KMP 
- H1g: Knowledge management resources can positively influence KMP

- H1h: Knowledge management conferences, training and education can positively influence KMP
The hypothetical model for the relationship is presented in Figure 1. The study examine the direct role of KMP in $\mathrm{OP}$ and subsequently examines the most key CSF that are supported in the implementation of knowledge management processes in a developing country like Nigeria.

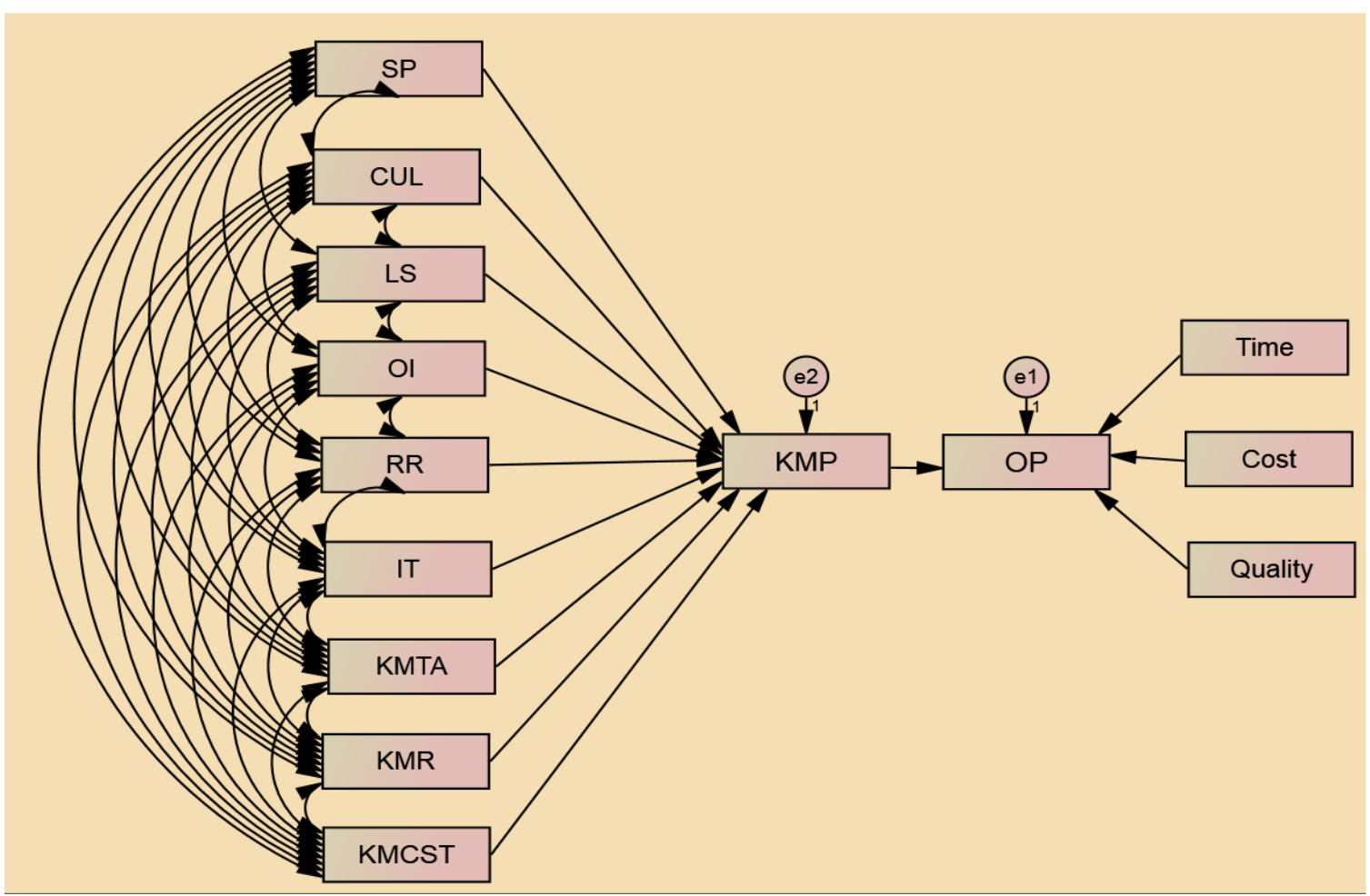

Figure 1: Hypothesized Measurement Model of the CSF and OP

Note:- (SP) Strategy, (CUL) culture, (LS) leadership, (OI) Organization infrastructures, (RR) rules/regulation, (IT) information technology, (KMTA) knowledge management technical authorities, (KMR) knowledge resources and (KMCST) knowledge management conferences and training, (KMP) knowledge management process, (OP) organization performance.

\section{Methodology}

The study employs a questionnaire approach in collecting data from the designated project managers in the construction industry. Multivariate method analysis to explore the relationship and covariance in the measurement model among the variables of CSF used. The method of the Structural equation model was adopted to test the index of the observed variables of
CSF of the KM process on OP from the hypothesized model. The causal relation between the observed variables and the causality in the models was determined using multiple regression model analysis method for the observed variables of CSF on $\mathrm{KM}$ process and vice and vice OP. Exploratory factor analysis (EFA), path analysis, regression analysis was used. First, EFA showing the CSF and OP with Kaiser-Meyer Okin measures with 
Bartlet's test (KMO) was found to be significant for all the observed variable at $<.001$. The maximum likelihood estimate for the items was adopted in dimension reduction. All CSF and OP that loaded $\leq 4.99$ were not considered for initial firstorder analysis as suggested by various researchers(Cohen, 2013; Coolican, 2014; Crockett, 2012). Thus, for initial confirmatory factor analysis (CFA), all CSF and OP factors that loaded above 0.7 were transformed to measurement model of an observed variable using SPSS version 22 as suggested by various researchers (Hair et al., 2006; Hancock and Mueller, 2013; Harlow, 2014). Two hundred and fifteen valid questionnaires were used from three hundred questionnaires distributed to qualified project managers in the construction industry. A stratified random sampling procedure was adopted and the questionnaires were distributed among eighteen construction organization.

\section{Data Analysis}

During the data analysis, normality and outliner, assessments were used for missing values through data screening. SPSS version 22 shows that only one variable had a missing data and means substitution method was used because the number is small as suggested by (Hancock and Mueller, 2013; Harlow, 2014). Thus, skew ness and kurtosis test with leaf plots was adopted to determine the normality distribution during the substation method of missing data. Virtually, all the variables lie between 327 and 0.74 for skew ness and $-1.350-$ 0.23 for kurtosis, which is within the recommended values of \pm 2 (skweness) and \pm 7 (kurtosis) by (Hirschberg and Humphreys, 2014; Hooper et al., 2008). Total estimate of kurtosis of the constructs is 47.596, which are also within the recommended values of $<50$ in an absolute world by (Kenny, 2011; Kline, 2006). Discriminant validity was evaluated based on the suggestion by various researchers that, the measurement model should be free from redundant items in the model in terms of modification indices (MI) (Kriston et al., 2008; Loehlin, 2004).

\section{Results}

The model unidimensionality is attained by deleting all factors loading < 0.6 , while convergent validity of the model is achieved using Average Variance Extracted (AVE) for every construct to be $\geq 0.5$ as suggested by (Marcoulides and Hershberger, 2014; Marcoulides and Schumacker, 2013). Composite reliability (CR) and internal consistency of the model were assessed and achieved with $\mathrm{CR} \geq 0.6$ as recommended by (Martínez-López et al., 2013; Mueller, 1997). Version 22.0 of AMOS (analysis of moment structure) was used to test model prudent. Each of the variables of CSF and OP in respective hypothesized model loaded $\geq 0.6$ as suggested by (Stevens, 2012; Ullman and Bentler, 2003) since the model acknowledges the data significantly, and MI was all less than fifteen in absolute figure as suggested by Wang and Wang (2012) and Zainudin (2012), the CSF data was transformed to an observed variable to measures the KMP. The OP was access using the traditional method of time, cost and quality. Internal reliability and consistency of the data were assessed using Cronbach's alpha coefficient, which shows $0.87,0.82,0.74$, $0.92,0.87,0.82,0.90,0.71$ and 0.70 for strategy, culture, leadership, organization infrastructures, rules/regulation, information technology, knowledge 
management technical authorities, knowledge resources and knowledge management conferences and training respectively. Time, cost and quality measures $0.70, \quad 0.81$ and 0.75 respectively. However, convergent validity of the model was achieved when all the items in the measurement model are statistically significant. Internal reliability shows how dependable (KMP) the measuring model in measuring the intend constructs (OP) as all the Cronbach's Alpha values calculated are all above $\geq 0.7$ suggested by various researchers (Nunkoo and Ramkissoon, 2012; Raykov, 2000).

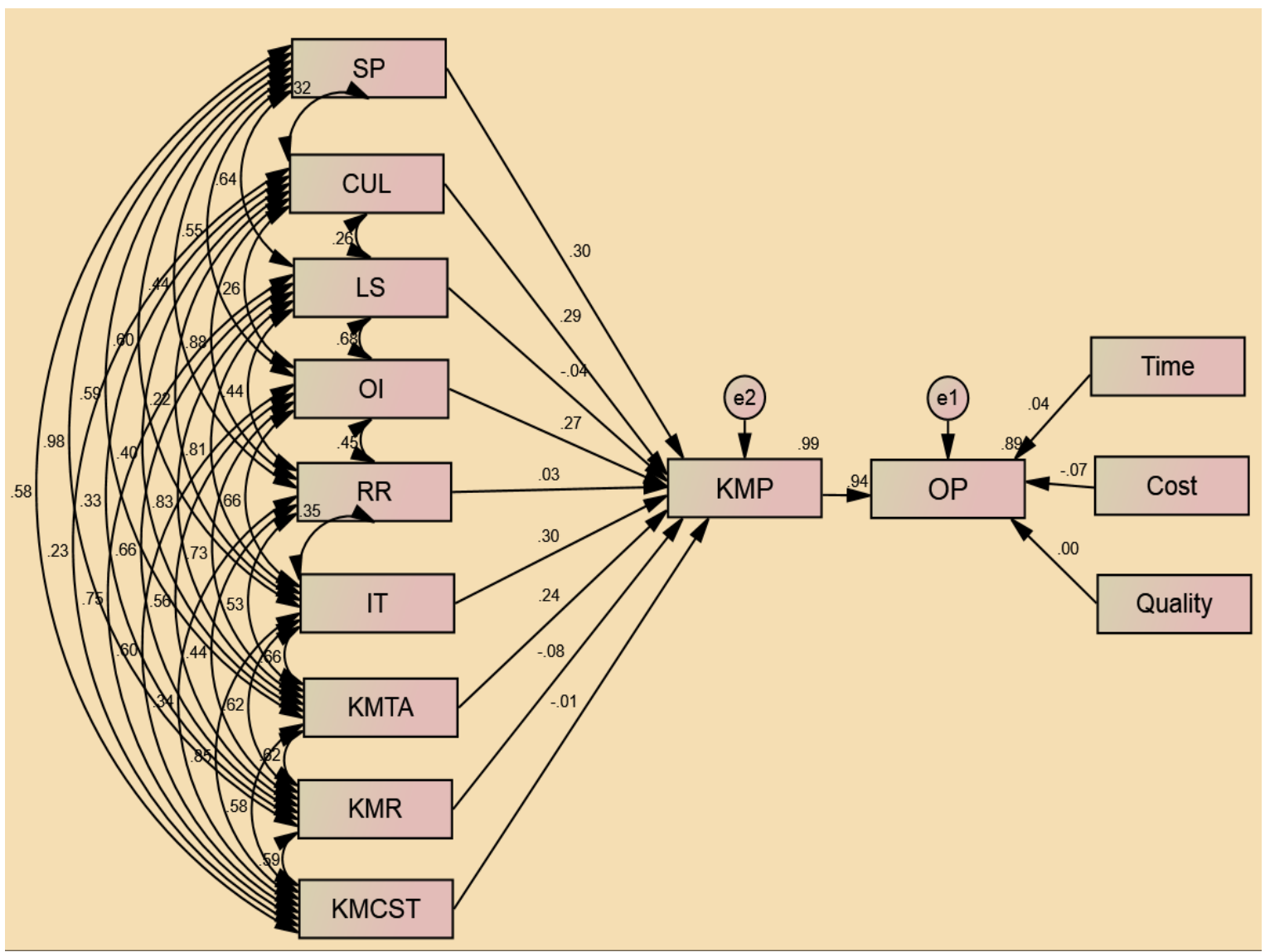

Figure 2: Measurement Model of the KMP influencing OP

Note:- (SP) Strategy, (CUL) culture, (LS) leadership, (OI) Organization infrastructures, (RR) rules/regulation, (IT) information technology, (KMTA) knowledge management technical authorities, (KMR) knowledge resources and (KMCST) knowledge management conferences and training, (KMP) knowledge management process, (OP) organization performance.

\section{Discussion}

The effect of KMP on OP was evaluated via Hypothesis 1 (H1) KMP OP with the sub hypothesis of CSF range from H1a (SP-KMP), H1b (CUL-KMP), H1c (LS-KMP), H1d (OI-KMP), H1e (RR-KMP), H1f (IT-KMP), H1g
(KMTA-KMP), H1h (KMR-KMP) and H1j (KMCST-KMP) as shown in Figure 1 and Table 1 . The path coefficient of 0.2 and above was measured as basically substantial loading (Zhong and Yuan, 2011). The result of confirmatory factor analysis demonstrated reliability and 
strong factor loading of KMP on OP (.94) as shown in Figure 2. The CSF of the knowledge management process measures $.30 .29, .04, .27, .03, .30, .24, .-$ $08,-.01$ for strategy, culture, leadership, organization infrastructures, information technology, knowledge management technical authorities, knowledge management resources and knowledge management conference and training respectively. The result analysis supported the hypotheses of $\mathrm{H} 1$ (main hypotheses) KMP-OP, H1a, H1b, H1d, H1f and H1e were all supported while $\mathrm{H} 1 \mathrm{c}, \mathrm{H} 1 \mathrm{e} \mathrm{H} 1 \mathrm{~h}$ and $\mathrm{H} 1 \mathrm{j}$ were not supported. Thus, it is suitable to assume that knowledge management process influences the organizational performance in the construction industry (Figure 2 and Table 1). The prime hypothesis is supported- H1; knowledge management process can significantly influence the organizational performance in the construction organization.

Table 1: Measurement of hypothesis and their path coefficient in the model

\begin{tabular}{llll}
\hline Hypothesis & Hypothesized path & $\begin{array}{l}\text { Path } \\
\text { coefficient }\end{array}$ & Result \\
\hline H1(KMP-OP) & $\begin{array}{l}\text { Knowledge Management process can positively } \\
\text { influence Organizational performance } \\
\text { Strategy can positively influence knowledge }\end{array}$ & .94 & Supported \\
H1a(SP-KMP) & $\begin{array}{l}\text { Management process } \\
\text { Culture can positively influence knowledge }\end{array}$ & .29 & Supported \\
H1b(CUL-KMP) & $\begin{array}{l}\text { Management process } \\
\text { Leadership can positively influence knowledge }\end{array}$ & 0.4 & $\begin{array}{l}\text { Not } \\
\text { supported }\end{array}$ \\
H1c(LS-KMP) & $\begin{array}{l}\text { Management process } \\
\text { Organizational infrastructures can positively } \\
\text { influence knowledge Management process }\end{array}$ & .27 & Supported \\
H1d(OI-KMP) & $\begin{array}{l}\text { Organizational rules and regulations can positively } \\
\text { influence knowledge Management process }\end{array}$ & 0.3 & $\begin{array}{l}\text { Not } \\
\text { Supported } \\
\text { H1e(RR-KMP) }\end{array}$ \\
H1f(IT-KMP) & $\begin{array}{l}\text { Information technology can positively influence } \\
\text { the knowledge management process }\end{array}$ & .30 & Supported \\
H1g(KMTA- & $\begin{array}{l}\text { Knowledge management, technical activities can } \\
\text { positively influence the knowledge management } \\
\text { process }\end{array}$ & .24 & Supported \\
KMP) & $\begin{array}{l}\text { Knowledge management resources can positively } \\
\text { influence knowledge Management process }\end{array}$ & 0.8 & $\begin{array}{l}\text { Not } \\
\text { Supported }\end{array}$ \\
H1h(KMR-KMP & $\begin{array}{l}\text { Knowledge management training, conferences and } \\
\text { seminars can positively influence the knowledge } \\
\text { management process }\end{array}$ & 0.1 & $\begin{array}{l}\text { Not } \\
\text { Supported }\end{array}$ \\
H1j(KCST-KMP) & & \\
\hline
\end{tabular}

Note:- (SP) Strategy, (CUL) culture, (LS) leadership, (OI) Organization infrastuctures, (RR) rules/regulation, (IT) information technology, (KMTA) knowledge management technical authorities, (KMR) knowledge resources and (KMCST) knowledge management conferences and training, (KMP) knowledge management process, (OP) organization performance.

\section{Conclusion}

The knowledge managers can adapt the application and can be cautiously modified. Observed variables of KMP and OP model display a useful degree of truthfulness as demonstrated in the SEM statistical indices. Knowledge managers, construction workers and researchers can both use established and validated model to increase the awareness of how 
knowledge management can influence organizational performance in the construction industry. Knowledge managers can use the model as a guide for organizational vicissitudes and researchers can use the model as a guide for further explore the possibility of other $\mathrm{CSF}$ in $\mathrm{KM}$ process. Although, a frugal model was achieved; it is liable to other confines; various studies through data collected from diverse sources are needed to boost both the stability and the sensibleness of the model. The research also discloses that strategy, culture, organization infrastructures, information technology and knowledge management technical authorities have an influence on the effective knowledge management process within the setting of hypothetical and skills of individual industry. The research finding can help organization's campaigners as well as professionals to improve and strengthened the surpassing role of the knowledge management process in the construction organization.

The research influence upon the body of knowledge in the various ways; first, the research produces a research model in empirical research that pinpointed the CSF in the knowledge management process based on the views of Nigeria construction organizations. Secondly, the researcher provides a research structure for researchers and construction consultants that are willing to conduct our research- related work in knowledge management in their organization.

Furthermore, the research adopted nine valid constructs for CSF that can be used as a reference to further studies. In this research, the hypothesis' model was validated through structural equation model in various model approaches such as Normality assessment, factors loading for each respective variable, and confirmatory factor analysis before transforming to an observed variable.
Many construction industries are still yet to understand the imminent gain of $\mathrm{KM}$ process to contest against foreign companies in our developing country. So, identifying the CSF in the KM process will go a long way to increase the organization performance. The Government should upkeep the construction industry by providing a promising environment for the knowledge workers and project managers to hold train professionals and engineers to coach other workers within the industry in order to advance the awareness of the knowledge management process.

\section{References}

Ahern, T., Leavy, B. and Byrne, P. (2014). Knowledge formation and learning in the management of projects: A problem solving perspective. International Journal of Project Management. http://dx.doi.org/10.1016/j.ijproman .2014.02.004

Balaid, A., Rozan, M.Z.A. and Abdullah, S.N. (2014). Conceptual model for examining knowledge maps adoption in software development organizations. Asian Social Science. 10(15): 118-132. URL: http://dx.doi.org/10.5539/ass.v10n1 $5 \mathrm{p} 118$

Bosch-Sijtsema, P.M. and Henriksson, L.-H. (2014). Managing projects with distributed and embedded knowledge through interactions. International Journal of Project Management. http://dx.doi.org/10.1016/j.ijproman .2014 .02 .005

Chen, M.-Y., Huang, M.-J. and Cheng, Y.-C. (2009). Measuring knowledge management 
performance using a competitive perspective: An empirical study. Expert Systems with Applications. 36(4): 8449-8459. http://dx.doi.org/10.1016/j.eswa.20 08.10.067

Chinowsky, P. and Carrillo, P. (2007). Knowledge management to learning organization connection. Journal of Management in Engineering. 23(3): 122-130.

https://dspace.lboro.ac.uk/2134/422 7

Choi, B. and Lee, H. (2002). Knowledge management strategy and its link to knowledge creation process. Expert Systems with applications. 23(3): 173-187. http://dx.doi.org/10.1016/S09574174(02)00038-6.

Cohen, J. (2013). Statistical power analysis for the behavioral sciences. Routledge Academic.

Cohen, J.F. and Olsen, K. (2015). Knowledge management capabilities and firm performance: A test of universalistic, contingency and complementarity perspectives. Expert Systems with Applications. 42(3): 1178-1188. http://dx.doi.org/10.1016/j.eswa.20 14.09.002

Coolican, H. (2014). Research methods and statistics in psychology. Psychology Press.

Crockett, S.A. (2012). A five-step guide to conducting SEM analysis in counseling research. Counseling Outcome Research and Evaluation. 3(1): $\quad 30-47 . \quad$ DOI: $10.1177 / 2150137811434142$

Dalkir, K. (2013). Knowledge management in theory and practice. Routledge.
Davenport, T.H., De Long, D.W. and Beers, M.C. (1997). Building successful knowledge management projects. Center for business innovation working paper. 4.

Donate, M.J. and de Pablo, J.D.S. (2015). The role of knowledge-oriented leadership in knowledge management practices and innovation. Journal of Business Research. $\quad 68(2)$ : $\quad 360-370$. http://dx.doi.org/10.1016/j.jbusres.2 014.06.022

Egbu, C.O. and Robinson, H.S. (2005). Construction as a knowledge-based industry. Knowledge Management in Construction. 31-49.

Hair, J.F., Tatham, R.L., Anderson, R.E. and Black, W. (2006). Multivariate data analysis. (Vol. 6) Pearson Prentice Hall Upper Saddle River, NJ.

Hancock, G.R. and Mueller, R.O. (2013). Structural equation modeling: A second course. Iap.

Harlow, L.L. (2014). The Essence of Multivariate Thinking: Basic Themes and Methods: Basic Themes and Methods. Routledge.

Hirschberg, N. and Humphreys, L. G. (2014). Multivariate applications in the social sciences. Psychology Press.

Holsapple, C.W. and Joshi, K.D. (2000). An investigation of factors that influence the management of knowledge in organizations. The Journal of Strategic Information Systems. $\quad 9(2): \quad 235-261$. http://dx.doi.org/10.1016/S09638687(00)00046-9

Hooper, D., Coughlan, J. and Mullen, M. (2008). Structural equation modelling: guidelines for determining model fit. Articles. 2. 
Jackson, L., Zuo, J., Zhao, Z., Zillante, G. and Feng, Y. (2015). Critical Success Factors for Refurbishment Projects. Proceedings of the 2015 Proceedings of the 19th International Symposium on Advancement of Construction Management and Real Estate: Springer, 1173-1182.

Jain, A.K., Moreno, A., Tuggle, F. and Ribiere, V. (2015). Organizational learning, knowledge management practices and firm's performance: an empirical study of a heavy engineering firm in India. The Learning Organization. 22(1): http://dx.doi.org/10.1108/TLO-052013-0024

Jennex, M.E. and Olfman, L. (2006). A model of knowledge management success. International Journal of Knowledge Management (IJKM). 2(3): 51-68. DOI 10.1007/s10796007-9053-4.

Jennex, M.E., Smolnik, S. and Croasdell, D. (2014). Knowledge Management Success in Practice. Proceedings of the 2014 System Sciences (HICSS), 2014 47th Hawaii International Conference on: IEEE, 3615-3624.

Kenny, D.A. (2011). Measuring model fit. Retrieved November. 29, 2011.

King, W.R., Chung, T.R. and Haney, M.H. (2008). Knowledge management and organizational learning. Omega. 36(2): 167-172.

Kline, R.B. (2006). Structural equation modeling. New York: The Guilford Press.

Kriston, L., Günzler, C., Harms, A. and Berner, M. (2008). Confirmatory factor analysis of the German version of the International Index of Erectile Function (IIEF): A comparison of four models. The
Journal of Sexual Medicine. 5(1): 92-99. DOI: $10.1111 / \mathrm{j} .1743-$ 6109.2007.00474.x

Liebowitz, J. (2006). Strategic intelligence: business intelligence, competitive intelligence, and knowledge management. CRC Press.

Loehlin, J. C. (2004). Latent variable models: An introduction to factor, path, and structural equation analysis. Psychology Press.

Marcoulides, G.A. and Hershberger, S. L. (2014). Multivariate statistical methods: A first course. Psychology Press.

Marcoulides, G.A. and Schumacker, R. E. (2013). Advanced structural equation modeling: Issues and techniques. Psychology Press.

Martínez-López, F.J., Gázquez-Abad, J.C. and Sousa, C.M. (2013). Structural equation modelling in marketing and business research: Critical issues and practical recommendations. European Journal of Marketing. 47(1/2): 115152.

http://dx.doi.org/10.1108/03090561 311285484

Mueller, R.O. (1997). Structural equation modeling: Back to basics. Structural Equation Modeling: A Multidisciplinary Journal. 4(4): 353-369.

DOI:10.1080/10705519709540081

Musa, M.M., Amirudin, R.B., Sofield, T. and Musa, M.A. (2015). Influence of External Environmental Factors on the Success of Public Housing Projects in Developing Countries. Construction Economics and Building. 15(4): 30-44. http://dx.doi.org/10.5130/AJCEB.v $15 \mathrm{i} 4.4514$ 
Nunkoo, R. and Ramkissoon, H. (2012). Structural equation modelling and regression analysis in tourism research. Current Issues in Tourism. 15(8): 777-802. DOI:10.1080/13683500.2011.6419 47

Raykov, T. (2000). On sensitivity of structural equation modeling to latent relation misspecifications. Structural Equation Modeling. 7(4): 596-607.

Stevens, J.P. (2012). Applied multivariate statistics for the social sciences. Routledge.

Ullman, J.B. and Bentler, P.M. (2003). Structural equation modeling. Wiley Online Library.

Wang, J., Li, Z. and Tam, V.W. (2014). Critical factors in effective construction waste minimization at the design stage: a Shenzhen case study, China. Resources, Conservation and Recycling. 82: 17. http://dx.doi.org/10.1016/j.resconre c. 2013.11 .003

Wang, J. and Wang, X. (2012). Structural equation modeling: Applications using Mplus. John Wiley \& Sons.

Zainudin, A. (2012). A Handbook on SEM Center for Graduate Studies: University Technologi MARA Kelantan.

Zhang, X. (2005). Critical success factors for public-private partnerships in infrastructure development. Journal of construction engineering and management.

http://dx.doi.org/10.1061/(ASCE)07 33-9364(2005)131:1(3)

Zhong, X. and Yuan, K.-H. (2011). Bias and efficiency in structural equation modeling: Maximum likelihood versus robust methods. Multivariate Behavioral Research. 46(2): 229265.

DOI:10.1080/00273171.2011.5587 36 